\title{
Discussion of Nursing Basic Teaching Reform under the Perspective of Computer Network Technology
}

\author{
Sulan Long ${ }^{1}$ \\ 1 Department of Nursing, Institute of Technology, Jiangxi University of Traditional Chinese medicine, \\ Nanchang, 330004, China
}

\section{Keywords:Computer Network Technology, Nursing, Basic Teaching, Reform Discussion}

\begin{abstract}
With the construction and development of the social economy, the rapid development of modern information technology, computer technology is widely used in various aspects of people's life and production, work, study, etc., to change people's perception of the world. The application of computer technology in nursing teaching process, to change the traditional mode of teaching nursing, nursing stimulate students' enthusiasm and initiative to enhance the quality of teaching nursing, for students to learn in terms of great significance. In this paper, the reform of nursing teaching Computer Network Technology to explore, and to this end a brief discussion by reference.
\end{abstract}

\section{Introduction}

Traditional nursing classroom teaching process, teachers dominate, full control of the classroom, in use for traditional teaching methods and irrigation duck style, emphasis on theoretical knowledge of nursing indoctrination, ignoring the understanding of the theory and application, and requires students mechanical memory of the way, recite various theories of knowledge, however, the effect achieved is not ideal. With the progress and development of our society, the rapid development of science and technology, information technology, so that our country has entered the Internet age, where computer technology has been widely used in people's daily lives. Application of computer technology in the teaching process has important significance of nursing, stimulate students' enthusiasm for learning and improve the quality of teaching, excellent transport a large number of nursing personnel in our society [1].

\section{The Application of Computer Network Technology in Nursing Basic Teaching}

Computer network technology, multimedia technology part of the core content, mainly constituted by the following parts, namely: The first video image processing technology second third voice processing technology, through the use of computer image signals, and thus information processing switching control storage and editing the various processes, the presence of multimedia technology and slide projectors, and many different application of multimedia technology in the teaching process, you can change the content of teaching methods and other means to promote change in the entire education sector, where, during the process of practical implementation of multimedia teaching, it should meet the following three conditions.

\section{A. The Aspects of Hardware}

Teachers prior to engaging in teaching should have a mature hardware. Among them, the hardware conditions is an important guarantee of multimedia teaching material to be implemented under normal circumstances, the multimedia classroom should have the following points, namely: 
computer projector speakers and audio CD machine, etc., should the school have a more favorable economic quality criteria, you can consider the use of a higher standard of hardware facilities, and the need to build a sound campus network system, you can create electronic preparation room for teachers, in addition, the need for teachers with a multimedia classroom, can effectively improve the teaching of nursing and efficiency.

\section{B. The Aspects of Software}

Software has become an important guarantee for the smooth development of multimedia teaching, can give full play to the role of the hardware has, which in the implementation of multimedia classrooms, the main contents include the following software following three aspects, first multimedia various disciplines teaching, are equipped with the appropriate tools required software products and teaching materials library; secondly, establish and improve multimedia teaching the required operating system and common software; third, look at the design of multimedia learning products, on the one hand, you can help students learn independently, on the other hand, can help teachers in teaching. For high-level part of the product, you can timely feedback to teachers of students learning and then according to the data provided, the students learn to analyze the situation [2].

\section{The Aspects of Teacher}

In the course of teachers in multimedia teaching, occupies an important dominant position, the level of overall quality of teachers directly related to the quality of teaching is good or bad nursing multimedia, teachers put forward higher to go, on the one hand, requires skilled teachers can operating the computer, on the other hand, the teachers are required to have a certain sense of innovation and application of advanced teaching philosophy in teaching nursing process in the classroom, the students on the advanced stage of the way medical care at home and abroad, showing a variety of academic achievement, to guide students to learn the professional content for expanded active discussion, in accordance with the needs of the proposed classroom teaching, multimedia teaching can be independently completed work.

\section{The Application of Multimedia Teaching in Basic Nursing Teaching}

\section{A. Improve the Efficiency of Classroom Time}

Traditional nursing classroom teaching process, teachers dominate, full control of the classroom, in use for traditional teaching methods and irrigation duck style, emphasis on theoretical knowledge of nursing indoctrination, ignoring the understanding of the theory and application, and requires students mechanical memory of the way, recite a variety of theoretical knowledge. This form of teaching on the one hand, increase students' academic burden, on the other hand, gradually erode the enthusiasm of students, classroom teaching cannot improve the quality of nursing, however, the multimedia classroom teaching mode in nursing in order to pictures, sound, text, audio, video and other forms to students presenting course content so that conventional complex abstract theoretical knowledge, become more intuitive and image, focus the attention of students and inspire students student enthusiasm, and thus enhance the students' the efficiency and quality of learning, teachers can shorten time to play board, shorten the learning time. In addition, the application of multimedia technology in nursing education classroom, teachers teach basic knowledge of the content at the same time, the content may be appropriately expand knowledge, so that students in classrooms with limited time to gain more knowledge content, so that students' horizons more open, more knowledge, to make up for the traditional teaching model drawbacks [3]. 


\section{B. Stimulate Students' Motivation to Learn}

According to psychologist noted that good motivation can inspire student learning initiative and enthusiasm, focus the attention of students, improve students' memory, in which the interest is the best teacher, the students have a strong interest in learning and the student's memory is in the best state to help students have better knowledge of the contents of memory to learn. Nursing classroom teaching application of multimedia teaching methods, can focus the attention of students, enhance students' motivation to learn, multimedia operation, so that the students involved in real situations, mobilize students to actively participate in learning to care through layers to help students better grasp of the knowledge learned content, promote the upgrading of the quality of nursing education [4].

\section{Enhance Students' Motivation to Learn}

Multimedia assisted teaching to enhance students' ability to care is important. Traditional teaching methods using face to face manner, students and teachers need to directly face to face, however, multimedia teaching methods, teaching status to change the past, teachers and students do not need to directly face the right, but the interaction between students and computers, students will be equipped with a computer, you can smoothly carry out the study, he pointed out that according to some students, assisted in the application of multimedia teaching methods to enhance its nursing learning initiative, students can independently control the speed of learning, improve student learning self-confidence, get more learning experience of pleasure, and thus enhance student achievement. in addition, students can develop good self-study habits, improve students 'innovation consciousness and ability to enhance students' self-learning ability to promote their care with a sound knowledge and become good caregivers.

\section{Building Online Learning Platform}

With the advent of the era of knowledge economy, education should focus on students learning, multimedia applications in the teaching process, resource sharing, remote teaching to enhance students' self-learning ability, background network information technology widely used in next, the nursing curriculum reform of the teaching model provides important material security [6]. The implementation of basic nursing online course is important, including the following points, namely: Course Announcements classroom learning garden and testing system, students can combine their own learning situation, log on to the network in the classroom, and then to knowledge consolidation , online course for students to create a good learning environment, while retaining the traditional classroom content, on the other hand, the modern teaching space to expand, will be connected to each other extracurricular learning and classroom teaching and promote students to actively explore and enhance students self-learning ability [7].

\section{Conclusion}

In summary, the use of multimedia in teaching nursing teaching mode, to change the traditional way of teaching and nursing means to image text voice and other forms to students presenting course content, encourage students to rational knowledge has improved, on the one hand, to raise basic nursing skills, on the other hand, enhance the quality and efficiency of nursing teaching classroom, prompting students can become good qualified nursing staff, in addition, feel the benefits of multimedia teaching methods at the same time, it should be recognized multimedia teaching drawbacks of each other, fully play an important role in promoting multimedia teaching methods to enhance the students. 


\section{Acknowledgment}

This paper is funded by Jiangxi 2013 Social Science 12th 5-Year Plan Project. Project NO. 13JY52

\section{References}

[1] Liu Huiling. nursing teaching reform based on computer networks and multimedia technology [J] Health Vocational Education, 2016,03: 75-76.

[2] Zhou Suzhen. of Basic Nursing Science Teaching and Multimedia Network Teaching Environment [J]. Science and Technology Innovation Herald, 2014,30: 124.

[3] Wucai Qin, Zhou Jie, "Fundamentals of Nursing" Teaching Reform Progress [J]. Nursing Research, 2013,35: 3978-3979.

[4] Zhou Suzhen. Basic Nursing Science Teaching and Multimedia Network Teaching Environment [J]. Science and Technology Innovation Herald, 2014,30: 124. 